\title{
A Profile of Fatherhood Among Young Men: Moving Away from Their Birth Family and Closer to Their Child
}

\author{
by Anne Quéniart \\ Sociological Research Online, Volume 9, Issue 4, \\ < http://uww. socresonline.org.uk/9/4/queniart. $h t m />$ \\ doi:10.5153/sro. 976
}

Received: 2 Jun 2004 Accepted: 26 Aug 2004 Published: 30 Nov 2004

\begin{abstract}
Have things changed all that much in terms of how fatherhood is conceptualized and exercised in daily life? That is the question underlying this article. The author compares the findings of a recent analysis on certain aspects of the lived experiences of young fathers (under 25 years of age) with the results of studies undertaken over the past ten years, and replies in the affirmative. First of all, when considering the representations held of fathers or mothers, most of these young fathers believe that their role is a multifaceted one, and that it is often identical to that of their spouse. According to young fathers, fatherhood is a dual experience that requires them to be present on a daily basis while also casting their eye on the future. This is an experience that is constructed out of affectionate moments, child-care duties, education in the literal sense, and especially out of shared experiences with their spouse. In addition, they question the degree to which involvement in a career should take precedence over involvement in their child's life. In other words, the former 'competes' with their ability to be present in their child's daily life, which denotes a change from the attitudes of previous generations.
\end{abstract}

\section{Keywords: Fatherhood, Young Fathers, Representation, Paternal Identity, Qualitative Research}

\section{Introduction}

1.1 As a category within the field of fatherhood studies, young fathers have been consistently overlooked. In psychological as well as sociological research, attention is focused either on fathers in general ${ }^{[1]}$, or on the specific experiences of teenage fathers in the wake of numerous studies on young motherhood ${ }^{[2]}$. All the same, this is an interesting category from a sociological point of view. Born between 1976 and 1984 , these young men are among the first to have been marked as children by the transformations affecting the family throughout the western world, from the declining number of children per family to the striking rise in divorce rates and fall in marriage rates. The young men interviewed for our study belong to this generation of children who grew up in smaller families (one or two children) with two working parents whom, in one out of two cases, are separated. Young fathers are also an interesting category to study because "the passage to adulthood" is a crucial period in the lives of young people. It is an important period in terms of self-definition and the construction of identity (Arnett, 1997). As well, it is also the time of their first significant involvement, not only with social institutions, including legal aspects such as reaching the age of majority and the accompanying right to vote, but also in terms of relationships (Gaudet, 2001). This is therefore a period when young people are confronted by the need to make choices at the personal and professional levels. In this respect, if young men decide to become fathers, this does not necessarily mean that they have reached other milestones along the path to adulthood, such as completion of their studies or entrance into the workforce. It should be remembered that, as Galland (1977) has shown, the ways of entering into adulthood have changed over the past thirty years. Certain stages associated with adolescence are prolonged nowadays, such as the greater length of time spent living under their parents' roof and pursuing their studies. In addition, there is also a desynchronization between the different milestones to be reached before entering adulthood, which have become somewhat independent of one another. This creates greater diversification in the trajectories that young people follow on their way to adult life. It goes without saying that the model of success that is the most highly valorized socially includes education (level of education, academic achievement), the start of a career, and financial independence. The trajectory of young fatherhood seems to jeopardize conformity to this model, which is what makes research on the representations that young fathers hold of this experience interesting. 
1.2 We chose to study young men who have become fathers in their late teenage years or in their early twenties in order to look at their personal experience with this hitherto unexplored rite-of-passage into adulthood. What does becoming a father represent for them? How do they juggle their life projects and their role as a father on a daily basis? What values do they privilege when defining their role as a parent? How are these values translated into their practical experience as a father? What representations of the child are associated with these values? These were the main questions guiding our research project ${ }^{[3]}$. This article will present some of our study's findings and will examine these questions in greater depth.

\section{Overview of the Literature}

2.1 Little sociological research, in Canada as elsewhere, has shown an interest in young fathers or even in fathers in general. On the other hand, fathers have been studied for almost thirty years within the discipline of psychology. After demonstrating that fathers are able to look after children "as well" as mothers do (Lamb, 1981), researchers turned their attention to the factors favoring fathers' active involvement in the family (Atkinson, 1987; Benokraitis, 1985; Volling and Belsky, 1991; Russell, 1982). Most studies in this field have concluded that various factors, ranging from personal to familial and social, contribute to fathers' involvement in the care of their children (Turcotte, 1994). These include the following: the representations that fathers hold of the family, the paternal role, and relations between the sexes (Crouter et al,1987); their feeling of parental competence or incompetence (McBride, 1989); their relationship with their own father (Barnett and Baruch, 1987); the age and sex of their child or children; the quality of the conjugal relationship (Perry-Jenkins and Crouter, 1990); their spouse's employment status (Benokraitis, 1985); and their attitudes towards work (their own and salaried work in general). Likewise, certain studies looking specifically at fatherhood in disadvantaged areas have highlighted the importance of self-perception and the role it plays in construction of the paternal role (Lévesque, Perreault and Goulet, 1997; Ménard, 1999).

2.2 This is also one of the observations that emerges from studies carried out in the domain of sociology (Ferrand, 1981; De Singly, 1993; Dienhart, 1998). Drawing inspiration from a re-reading of the history of relations between the private and public spheres, some researchers analyzed fatherhood as a cultural construct that varies over the course of history and between social groups. This work shows that fatherhood has taken on several different forms between the 18th and 20th centuries. The first is that of the "American colonial father" (Rotondo, 1985) or the European "rural patriarch" (Castelain-Meunier, 2002), who was highly present in family life on a daily basis and whose role was that of a guide and teacher, especially for his sons. The second form, that of the father as "head of the family" emerged during the Industrial Revolution, where the father was not very present at home but was financially responsible for his family through his work. The third form appeared in the 60's and is characterized by its complexity. Here, the father is supposed to be present in home life, involved with his children, capable of expressing his emotions, and fulfilled by his work while being economically responsible for his family at the same time ${ }^{[4]}$.

2.3 Other researchers have been more interested in representations held of the paternal role that emerges from the discourse of fathers themselves (Lamb, 1987; lishii-Kuntz, 1994; Fournier and Quéniart, 1994; Dycke and Saucier, 1999; Quéniart, 2000, 2002a). This body of work shows that there is more than one way of being a father today, and that this varies between cultures and social milieux. Despite the diversity of models that now coexist, researchers nonetheless agree that three ideal-types of fatherhood can be distinguished. The first harks back to the traditional father, also called the provider father (Fournier and Quéniart, 1994; Lévesque, Perrault, and Goulet, 1997; Quéniart, 2002a) or the autocratic or patriarchical father (Broderick, 1977), whose role is essentially reduced to an economic and authoritative one and whose relations with the child are mediated through the mother. The second type is represented by the "new" father (Delaisi de Parseval, 1982; Dienhart, 1998), sometimes also called the androgynous father (Rotondo, 1985; Robinson and Barret, 1986; Verheyen, 1987), the co-parent (Russell, 1982; Palm and Palkovitz, 1988), the expressive leader (Broderick, 1977), or the substantive father (Ferrand, 1981). Here, the father's multi-dimensional role encompasses relationships, education, and financial responsibility, and his relations with the child are personal, direct, and affectionately demonstrative. A third type emerges from certain studies, called the assistant-parent father (Russell, 1982; Palm and Palkovitz, 1988), the complementary father (Ferrand, 1981), the typical father (Robinson and Barret, 1986), or the teflon father (Fournier and Quéniart, 1994). In this case, the father's role borrows certain elements from the "new" father (a personal relationship with the child) as well as from the traditional father (mediation through the mother, importance of the provider role).

2.4 Once having described these diverse representations of fatherhood, some researchers have tried to discern the variations that exist between social milieux. Although each of these representations can be held by fathers from different social milieux and of different ages, studies have shown that the model of the provider is upheld mostly among fathers who are older, less educated, and whose work permits little opportunity for initiative in relations with their children. Likewise, the model of the "new" father is found more often among fathers who are well educated and whose spouses have always been in the workforce. Lastly, 
among the youngest fathers, the model that prevails is that of a father torn between fatherhood and work. This is found across the board, among fathers who are well educated, who hold highly respected positions at work, and whose spouses are not financially obliged to work, as well as among fathers who, on the contrary, have difficulty entering the job market or in re-entering it, following a period of unemployment, for example (Erickson and Gecas, 1991; Lévesque, Perrault, and Goulet, 1997).

\section{Methodological Aspects of the Research Project}

\section{Choice of approach}

3.1 In terms of methodology, we opted for a qualitative approach since we were interested in the meanings that young fathers themselves assign to the experience of fatherhood. More precisely, we chose grounded theory analysis (Glaser and Strauss, 1967; Glaser, 1978; Strauss and Corbin, 1990). This method is appropriate in the case of social phenomena that have been little studied, and for analyzing the meanings accorded by social actors to life experiences that concern them directly.

\section{Respondent selection and characteristics}

3.2 The respondent sample is composed of 32 young fathers living in Montreal, Canada, who were recruited voluntarily through a variety of sources, such as ads in the paper, student associations, adult education facilities, daycares, etc. In accordance with grounded theory, respondents were selected from a diversity of situations, including conjugal status (married, common-law, separated), parental status (father of one or more children, etc.), and socio-professional status (employed, stay-at-home father, student, etc.). Young fathers in this study only had to meet two strict criteria - they had to be less than 25 years old, and be the father of at least one child who was at least one year old.

3.3 Of the 32 young fathers ${ }^{[5]}$ in this sample, all were between the ages of 19 to 26 at the time of their interview, and all had had their first child between the age of 17 to 24 , with the average age being 21.4. Three fathers were separated from the mother of their child, and another had never lived with the mother of his child. The others all lived with their spouses - 8 were married and 20 were living in common-law relationships. 15 fathers either had a high school diploma or had left high school before graduating (leaving in Grade 9 or 10). 7 had a college or professional/technical diploma at the Quebec provincial CEGEP ( college) level, 7 had a Bachelor's degree, one had a graduate-level certificate, and 2 were working towards their Master's degree. Their personal annual income varied from below $\$ 12,000$ to over $\$ 40,000$. 12 made $\$ 15,000$ a year or less, 4 made over $\$ 30,000$, and the remaining 16 all had annual incomes of between $\$ 15,000$ to $\$ 30,000$. Thirteen worked full-time and three part-time. Two were receiving unemployment insurance benefits at the time of interview, and the remaining nine were working and studying at the same time, either full-time or part-time. Two of the young fathers interviewed for this study had two children at the time of interview. Five others had had one child already and were awaiting the birth of their second child. Two other young men lived in blended families that included their spouse's child from a previous relationship - one of these two couples had had their own child as well, and this father was caring for two young children. The remaining twenty-three fathers had only one child each.

\section{Interview process and analysis}

3.4 The interviews were an average of 90 minutes in length. Two-thirds were carried out in our offices at the university, while one-third took place in respondents' homes. During the interview, young fathers were invited to "tell us about their experience as a father". According to the principle of grounded theory, we let the topics that they felt were important to understanding their lived experience emerge on their own. However, for comparison's sake we took care to ensure that certain topics were systematically covered by all respondents. To this end, an interview schedule was developed that included the following main topics: the context of the child's birth, the relationship that young fathers have with their families (representations, daily practices), and the meaning and place granted to fatherhood in their personal lives, spousal relationships, and professional and social lives.

3.5 All the interviews were tape-recorded. They were then faithfully transcribed and both vertical and horizontal qualitative content analysis was performed. Vertical analysis (analysis of interview content) was performed first, and involved three steps. First we pinpointed and coded the topics that were either proscribed by the interview schedule or that emerged during the interview itself (context of the pregnancy, reactions of family and friends, activities carried out with the child, etc.). We then grouped this information into categories (importance of being close to the child, the child as an extension of the self, etc.). And last, we elaborated hypotheses in order to interpret the discourse of young fathers. Once this was completed, horizontal analysis was performed in order to compare the content of young fathers' discourse according to the relevant independent variables (conjugal situation, occupation, etc.) and to refine the categories that 
were created before. At this point, it was observed that the saturation point had been reached for most of the topics.

\section{Discussion and Analysis of Results}

4.1 In this article, we will focus on some of the dimensions that emerged over the course of interviews with young fathers, including what fatherhood means for these young men and how it unfurls in their daily lives. As we will see, intimacy "management" is of the first order for these young men, since asserting independence from their parents and relatives through construction of their own "physical space" is highly desired. This indirectly affects the composition of their social circle, since loss of their former social circle is either experienced as suffering or mourning for a past youthful life or else is it appreciated and even sought after since it corresponds better to their new life as a father. Lastly, we will show how paternity is linked with proximity for these young men. For them, fatherhood is above all an emotional relationship. This fits in well with the growing tendency of modern families to withdraw into their own emotional world, even to the extent of closing themselves off from all outside influences.

\section{The boundaries of fatherhood, or how to construct a private space}

\section{Keeping parents at a distance}

4.2 Among most of the young fathers interviewed, paternal and parental independence is claimed very strongly from the time that the pregnancy is first announced. The new "household", the primary symbol of privacy and intimacy, closes off to all outside interference. Paradoxically, the birth family represents the main source of support for the new parents-to-be in various ways. This can include loans or gifts of money, provision of all or many of the items that will be needed once the baby is born, and provision of unflagging baby-sitting assistance. Above and beyond helping to provide material assistance or "parental relief", the birth family is also a decisive locus of social confirmation. From the time the pregnancy is first announced, the parental circle generally gives young men the potential required to fulfill their parental functions while guaranteeing support and help for the new family. This infuses the father-to-be with the confidence he needs to take on this new role and the responsibilities that come with it.

4.3 Although the majority of respondents had already moved out of their parents' home before their first child was born (25 of the 32 fathers encountered), complete independence from their parents does not seem to have been entirely achieved. For most of these young fathers, however, the time does come when boundaries between their new family unit and their birth family must be established. Privacy becomes a central issue, one that requires negotiations to occur between these two polarities. Simply put, the new family unit claims its independence. This stage is also the time when these young men tend to affirm their definitive transition into the "adult world" to their friends and other members of their primary social circle.

"I began working much harder. I could've worked less and asked my dad for help. He offered to when I told him we were going to have a baby, he said he'd help out financially. We didn't take him up on it. Since Claudine thinks like me also, we managed to get by. I told myself, you want the baby, so show you can look after it, otherwise they're always going to say it was a mistake cause I was way too young. But if you show right away that you can manage without anybody's help, in the end they'll just say, so he was 19 instead of 25, it's worked out alright." (William, 22 years old, technical/professional college diploma, a three year old child).

4.4 In all these cases, independence was still greatly sought after even though they remained dependent on their birth family. Compromise between some fathers and their birth families was easily made, and the occasional offer of help or advice was even appreciated. For others, the search for independence led to heightened tension in their relationship with their birth family. Whatever type of support the immediate family circle offers, interference with the private decision-making powers of these young fathers is not allowed. Management of the private realm is usually jealously guarded. No matter how much help young fathers receive from their parents, the latter are still not allowed to have too much input into their grandchild's education.

"She's not the child's mother, she's his grandmother, she's my own mother. Stop giving me your opinion on everything, I don't need it. [...] My mom sort of meddles in your private life, you can't do anything about it. It gets annoying at a certain point, its easy to say I want to help, I want to support you, well support me but let me make my own choices anyways." (Mathieu, 24 years old, Bachelor's degree, a three year old child).

4.5 Some respondents bring up new scientific findings and thinking (usually in the field of psychology) to explain why they feel that their birth families' modes of parenting are obsolete and out-dated, particularly in terms of education. 
"We don't have much confidence in our parents and so we said we'd go talk to an early childhood educator. [...] We take some of our parents' advice, but not too much because we find that their ideas are a little behind the times, my parents are 40, 46 years old [...]." (Étienne, 24 years old, Bachelor's degree, a three year old child).

4.6 In short, it's a matter of making their limits known regarding this well-intentioned interference. Concerned about its independence, no matter how virtual this might be, the new family unit then establishes a working arrangement that sets out the distance to be respected by others. If this request does not obtain the hoped-for response, the birth family's attitude is perceived as being interference, and loses all legitimacy. The rift then widens further, making access to the child something that needs to be protected even more. Notions of freedom and choice seem be prioritized by most of our respondents. Some even preferred to limit the assistance offered by their family network in order to preserve their power within the new family unit, which was still in its infancy itself. Establishing independence then sometimes occurs via financial independence.

\section{Rebuilding their social circle}

4.7 For young fathers, the birth of their child implies putting distance between themselves and their parents. However, this has the indirect and unwanted effect of eroding the way of life associated with ego, of relegating it to second place. For most of these men, their personal time before the birth of their child was divided between going to school, holding a job (usually part-time), nurturing their conjugal relationship, and spending time with members of their social circle. Other respondents lived mainly for their repeated travels world-wide. Before the birth of their child, the majority of respondents had a lifestyle that corresponds with that of today's "youth culture". Just before the pregnancy was announced (an accidental one for 24 of the 32 fathers interviewed), their introduction to adult life seemed to unfold progressively. Like many young people, the definitive moment when they would have to cross over the threshold into adulthood was being postponed. However, fatherhood profoundly upset the form that their trajectory towards adulthood was taking, and the massive degree of involvement and commitment that this new life situation required provided the impetus that propelled them towards adulthood ${ }^{[6]}$. Despite the fact that respondents could be described as being "young people", their current lifestyle is quite removed from their former lifestyle and way-of-being. Their priorities turn first to their child, and then to their conjugal relationship and career (or studies). The importance that they used to attribute to their social circle has been altered from this point on. This change represents the greatest transformation encountered since the birth of their child. For some, these friendships have been completely dropped, becoming part of their biographical past. While these friendships constitute a polarity that is directly opposed to fatherhood, this is also the thing that young fathers miss the most about their former life.

"Do I see my friends, that's a very very good question, I hardly ever see my friends anymore. [...] I always hung out with my friends before, there was a whole group of us who went out together, but now I'm not really part of that group anymore." (Étienne, 24 years old, Bachelor's degree, a three year old child).

4.8 For others, this change happened gradually due to a decline in get-togethers with friends and to modifications in their relations with them. However, they report that this has not affected the quality of their relationships all that much. In other cases, fatherhood is the final act in a purification ritual that had begun well before. They re-focused their attention on several close relationships, alienating the peripheral strata of their social circle at the same time.

"Another thing I've done with my life, I've tidied up my friendships. I realized that I hadn't chosen my friends myself, it was like a clique. Once I stopped drinking, it's been boring for me, since these friends are all drinkers. l've stopped seeing them in order to spend more time with the people around me who don't drink." (Samuel, 25 years old, high school diploma, a six year old child, separated).

4.9 How can this disinvestment of old friendships be explained? During our interviews, respondents sometimes blame lack of time and energy, a situation that respondents link to the vastness of their parental responsibilities. Others also mention lack of available funds, with also limits the possibility of going out with friends. As the only breadwinner, the cost of a baby-sitter alone is enough to decrease the need of some young men to go out with their friends. But we also noticed that entering fatherhood shapes their existential perspective, transforming it as well. Their child and spouse become the focal point of their lives, rendering relations with others more and more uncomfortable.

"I also don't have as much in common with them anymore, they're a little young, maybe they're, well, they're the same age as me, but l'd say that maybe I've gotten more mature 
since l've had my child, they're still at the stage where they want to go out all the time [...]. Some of them smoke up cause they haven't really evolved very much so sure its hard to see them a lot, you can really see that you don't do the same things that they do anymore." (Max, 23 years old, Grade 9, raising two children - a one year old child of his own and his spouse's child from a previous relationship).

"Everything in my life has changed basically. When she was born, I still hadn't finished Grade 11 yet and I was going out all the time and I saw my friends all the time whenever I wanted to. Since she was born, I finished Grade 11, I've started CEGEP, and I see my friends a little less but that doesn't bother me. Being able to spend an evening with my daughter, it's something I enjoy a lot more than going out for a beer. All this woke me up, in terms of friends, school. I find I'm more mature than I was a couple of months ago." (Francis, 21 years old, high school diploma, a one year old child).

4.10 Only several of the fathers we encountered included friends of the same age who are also fathers in their social networks. For the others, the isolation of their situation crops up more than once in their discourse. Their friendships do not seem to give them any positive feedback on their paternal experience. Fatherhood seems to individualize their trajectories from those of their peers, which instigates a process of detachment from them at the same time. However, there does not seem to be any rule that we might employ here to affirm that young fathers' estrangement from friends automatically corresponds with the act of shifting their priorities from their friends to their new family. Some of these fathers have managed to preserve strong ties with members of their social circle. One of the solutions that allows them to continue their relationships with their friends involves switching back and forth between their life as a young person and their life as a parent.

"Fridays are for me, to relax, to think about things, to go and see my friends because I don't see them all week, cause like I tend to shut myself up at home. I go to sleep early cause I have to wake up early. Fridays, I reserve for my friends." (Simon, 19 years old, Grade 10, one child just over a year old).

4.11 But for many, the idea of carrying on a double life as a young person and a father engenders a profound feeling of guilt, since they consider this to be egotistical with respect to their child. At the time of interview, the relationship that these men have with their children can sometimes be described as a "calling" - their fatherly aspirations mobilize the very essence of their being, which puts into question even the simple idea of taking time for themselves. The internal conflict that some of them suffer seems to be appeased if the child also has the occasion to have fun (staying at a friend's house, for example) during the time they are out with their friends (at a bar, having dinner together, going to the movies, etc.).

4.12 Another way of managing friendships is by integrating "outside social activity" into the family circle. The attraction of pursuing activities with friends at home likewise transforms the way friendships were formerly conducted. Now they have dinner together at home, play Monopoly, etc. From our point of view, it is interesting to note that the attraction of the private realm leads many men to re-evaluate their need to go out with friends. Once they finish mourning for the carefree life of their youth, they seem to develop a genuine sense of attachment to a more domesticated and quiet family life.

"You could say that l've rediscovered my home. Before, it was just a place to sleep or be with my girlfriend. Now its more like a home, since l've like taken to spending more time there, its like, you could say that when you have a child, your bubble grows a little larger. [...] There's a sense of communion that happens." (Richard, 24 years old, college diploma, a two year old child).

"We do more things at home. We never really go out to bars anymore. We have a lot of people over. That's really where things happen, we entertain a lot. [...] With a child, you don't do the same kind of activities, you'll choose something you can do with your baby. It's more quiet to a certain extent, for sure." (Adam, 25 years old, Bachelor's degree, a 10 month old child).

4.13 Friendships are then continued in a new way as long as they are reconcilable with the private realm. This is a condition of friendship that does not always have the hoped-for response. It seems that several times, friends did not appear to be entirely at ease with the intimacy of this milieu. Several respondents described the reluctance of some friends to integrate into their family life. Thus, intimacy and privacy can also lead to isolation. 
4.14 As one may observe from these young fathers' stories, the child occupies a central place in their life. More accurately, the child occupies the base of the decision-making pyramid from which these young men organize their activities. The primary position occupied by the child corresponds with the way that these young men define the father's parental role. This tends to be based above all on the father's continuous presence in the child's life, and on a vision of the father as "advisor".

\title{
Being present in the child's life and showering it with affection
}

4.15 What does "being a father" mean in actual fact? Being present in the child's life is a leitmotiv used by all the young men interviewed. This means being present through play, but also through "basic care-giving". In short, it means being present in all aspects of the child's daily life.

\begin{abstract}
"It demands an enormous amount of love and attention. Actually, it means being there all the time, always being attentive, holding it. I don't believe in not seeing your child during the week. I think that your child has to learn to understand you as much as you learn to understand it, and this, this is something that happens every day, it's a part of daily life, it means always being available, always being there in a certain way." (Charles, 19 years old, high school diploma, working in a plastics factory, a one year old child).
\end{abstract}

4.16 This desire to be present manifests itself in diverse ways on a daily basis. For some, the time they have available to spend with their child and spouse is limited to evenings and weekends due to their heavy work schedule. These fathers place more emphasis on the quality of their relationship with their child and on the existence of a "good baby-sitter" or a "daycare that gives the child as much affection as we could give it ourselves". For others, the need to be present and available led to drastic changes in their professional life. This ranges from questioning the viability of a career overseas to choosing part-time work or a more flexible work schedule.

4.17 Being present in the child's life also involves purely affectionate moments, without recourse to any other activity. Among other things, these moments are meant to shower the child with love in a way that "transcends language". For these fathers, it is not only a matter of feeling love for their child, which in some ways forms the core of the relationship, but also of showing love by being present in the child's daily life and by playing with it. In doing so, they hope that this will ensure closeness between father and child.

"When she, when she wants to watch tv, I'm not going to go and clean the house during that time just because she wants to watch tv. I'd rather go and curl up with her, sit down next to her, and why not. It doesn't matter if the show is boring, I close my eyes and she leans against me, I can relax just being with her." (Mathieu, 24 years old, Bachelor's degree, a three year old child).

4.18 Close ties are then also formed through purely physical contact in a shared space. While this connection with the child is based partly on the love the father feels and shows for the child, the physical connection between father and child means that the connection is constantly under construction. These young fathers seem to exemplify the features of the contemporary family, which De Singly (1993) refers to as the "relationship-based family", where the emotional connection is the dimension that predominates. In this schema, the child occupies a central position. Thus, one of the basic principles of parent-child relations in this model (and also one of the reasons for a rupture in relations between father and child) has to do with the way that emotion and affection is expressed and communicated.

\section{Being the guiding light, not an authority figure}

4.19 For many of the young men interviewed, being a father also means being the child's "advisor". Therefore, instead of just forbidding it to do something, they prefer explaining the reason why as openly and honestly as possible.

"The parent's role is to give to the child, not to impose things on him, but to instill certain values in him, and to cultivate his imagination." (Richard, 24 years old, college diploma, fulltime student).

4.20 The father is seen as being the child's guiding light, indicating which roads he can possibly take without telling him which choices to make. Moreover, this vision corresponds with the very qualities that they feel should be developed in their child, as these will be needed for its on-going advancement within society. These qualities are confidence, independence, and the ability to make appropriate choices. In other words, the discourse of these young fathers seems to suggest that the child needs to begin learning how to select from among all available options right from the start, in order to be able to move comfortably later on through a world characterized by self-reference and highly individualized life trajectories. The father's job is 
then to accompany his child in this selection-making process, to be there for him during decision-making dilemmas, and to inculcate the idea of responsibility in him. The father then appears to be a source of information for his child, a guiding light that can illuminate all aspects of the child's life without making his choices for him.

4.21 In many interviews, respondents are clearly distancing themselves from the father's traditional role of authority-figure within the family. Even if these fathers appear to be the parent who tends to be the most authoritative ${ }^{[7]}$, they often feel that this is by default or out of exasperation. Either they feel they are "too impulsive" and are not well-equipped enough to intervene properly in the child's outbursts or tantrums (or are too "impatient", as many told us), or else they act like that because they feel that their spouse is "too permissive". Nevertheless, whatever the cause might be, this attitude does not coincide with their ideal conception of a father. On the other hand, being a hardened disciplinarian does not seem to be a component of their daily actions as a father. It is used only occasionally and must always be justified. Actually, some wanted to move away from the ways-of-doing that they learned in their first social circle, that of their birth family. More specifically, they sometimes consider their own father to be an anti-role model, not in terms of all their father's paternal actions, but more in terms of the way he administered his authority.

4.22 Nonetheless, this reduction in authority does not mean that it has been done away with altogether. During our interviews, fathers gave no indication of having abdicated their recourse to authority, or that the administration of authority had dissolved under the weight of the rights attributed to childhood. On the contrary, several of them expressed a phobia of the "child-king", and this was something that motivated them to intervene as a disciplinarian. For these fathers, this power must be used in the right way and the parties under litigation should be encouraged to try and talk things over first. Many expressed the hope that emotional closeness with their child will be preserved on a long-term basis, and a relationship based on good communication is believed to reinforce this. Being present in their child's life does not only mean being involved in practical day-to-day matters, it is also something that requires continuous effort and an eye trained on the future. They believe that they have a particular advantage over other fathers, feeling that as young fathers they will have the energy needed to actively maintain their relationship with their children for a long time, even after their children reach adulthood.

\section{Being someone whom the child can count on}

4.23 Lastly, for the young men interviewed for this study, being a father means being "someone whom your child can count on all its life". For many, fatherhood was experienced as a process of taking on responsibility. This is notably the case among those for whom the conception of their child was unexpected ${ }^{[8]}$. For them, the expression "being responsible" covers several meanings that correspond well with the polysemy of the term, which has both moral, legal, and philosophical connotations. First of all, it involves the standard meaning of a "person's obligation to respond through action according to his role and the responsibilities that he must assume, and to accept all the consequences of these actions"[9]. Once the child is born, being responsible therefore means agreeing to assume financial responsibility, either by changing jobs or by returning to school. This means "taking yourself in hand", as one young father said, since "the life of a little being now depends on you". In other words, this means accepting responsibility, looking into the future, and having a long-term vision of what the arrival of the child in their life means. This is also why some young fathers were led to make changes in their career.

"In the hospital, its very emotional, you're like immersed in emotion, and as soon as you leave the hospital, and you're with your child, that's when everyday life begins, everything's got to be reorganized. You've got to find a job that's fairly well paying [...] in order to support the three of you, you've got to have another room, buy clothes, diapers, bottles, and this and that." (Samuel, 23 years old, a four year old child, separated, high school diploma, receiving unemployment insurance benefits).

"Before she told me she was pregnant, I'd started a three-year CEGEP program in theatre but you know, there's no real guarantee of making any money in theatre. Myself, I can live with that but you also have to think of what work you can get later on. I found something else that will pay well and that I like also. For now I'm working with plastics but l've registered for the fall in industrial service technology." (Charles, 19 years old, high school diploma, working in a plastics factory, a one-year old child).

"Let's just say it put everything in question. You always see your life going in a certain direction and when your baby's born, it changes your plans a little. We thought we'd travel a couple of time, stay in our little apartment, and also get our studies done quickly before finishing off with a Master's. [...] From the moment we learned of it, we only studied part-time because we had to work more to get some more money." (Adam, 25 years old, Bachelor's 
degree, student and research assistant at a university, a one-year old child)

4.24 Among respondents for whom the pregnancy was planned (the most educated and oldest of the entire sample), the notion that responsibility means being able to plan for the future also existed. However, they emphasize future financial responsibility less than emotional responsibility. One father expressed this very well when he said:

"I realized that all of a sudden, you officially matter to someone, or actually, not that you matter to someone, but that there's someone who depends on you" (Richard, 24 years old, college diploma, part-time student, a one-year old child).

In other words, being a father also involves the self-awareness of being a "significant other" for someone who is dependent or fragile.

\section{Conclusion}

"The culture of the subject that valorizes the intimate more also represents a value that is growing among young men, who can now imagine affirming themselves more independently in private life and pursuing fatherhood in a hands-on way" (Castelain-Meunier, 2002: 153-154).

5.1 The young fathers in this study seem to have adopted as their own the traits of the contemporary family, also known as the "relationship-based family" (De Singly 1993). Here, the emotional dimension predominates, as well as the central place granted to the child, the desire to interact with the child on his own level, and the need to be attentive to what he says. One might say that these young men are representatives of the "new" fatherhood, which is not a passing fad but the result of transformations in family, parental, and masculine values. This "new" type of fatherhood is rooted in many currents, including representations of the child that emerged after the Classical Age, the anti-authoritarian and egalitarian principles of counter-culture, new forms of male-female relations in the domestic sphere (equality between the sexes, sharing chores), and transformations to notions of masculinity (the reconnection of men with their emotions and intimacy). Relations with their child are coloured by the centrality of the child in their life, by the desire to respect some of the rules of the game that he has devised, and to be attentive to what he says. For these fathers, the child is seen for himself, for who he is, as a "person-to-be", whose potential should be developed fully rather than restricted. This receptivity and mode of paternal availability to the child are striking elements in every interview, and convey very well the elements of the "new" fatherhood among young fathers today.

5.2 Moreover, although many young men brought up the necessity of "working to support the family" during their interview, this appears to be one of the responsibilities that follows from the arrival of the child in young men's lives, and is not essential to the production of their paternal identity. Above all, it is a responsibility that does not belong only to the father. For these young men, attending to their family's needs is one of the obligations and necessities of both parents, and does not constitute that which defines them as fathers, as opposed to men of previous generations. And conversely, some also said that work should not occupy too much space in their lives.
"Before we used to say that the father brings home the bacon. Today, its not really like that anymore, its pretty well shared. A father who works too much, who isn't there for his children, well, I don't think its good. [...] A father's someone who works but who's also there for his child, to be with him, to listen if he needs to talk, for his little problems." (Alexis, 19 years old, Grade 10, receiving unemployment insurance, a one-year old child).

5.3 In other words, for the young fathers interviewed for this study, involvement with their child puts their level of professional involvement in question. One might say that professional involvement "competes" with their ability to be there for their child, which denotes a change with respect to previous generations, at least in terms of the aspirations and norms of fatherhood.

\section{Notes}

${ }^{1}$ Refer to Ferrand (1981), Bozett and Hanson (1985), Lamb (1987), Bronstein and Cowan (1988), and Delumeau and Roche (1990), among others.

2 Refer to Robinson (1988), Kiselica (1995), and Cournoyer (1995), among others.

${ }^{3}$ This research project was funded by the Conseil québécois de la recherche sociale (Quebec Council for Social Research). 
${ }^{4}$ Regarding transformations to the paternal role, refer among others to Delumeau and Roche (1990) and Neyrand (2002) for France, and Dulac (1993) for the province of Quebec, Canada.

${ }^{5}$ Young fathers were recruited from various sources in Montreal: CLSC workers, personal contacts, ads in different papers.

${ }^{6}$ Refer to Quéniart (2002a) for this aspect of the lived experience of young people.

7 This is an observation that also comes up during interviews currently being conducted with young mothers.

8 This was the situation for three-quarters of fathers interviewed for this study. For more details on this issue, please refer to Quéniart (2002b).

${ }^{9}$ Encyclopédie philosophique universelle. Tome II. Les notions philosophiques: p. 2250).

\section{References}

ATKINSON, Alice M. (1987). "Fathers' Participation and Evaluation of Family Day Care", Family Relations, vol. 36, no 2, 146-151.

ARNETT, J.J. (1997). "Young People's Conception of the Transition to Adulthood". Youth and Society, 29, 1, p. 3-23.

BARNETT, Rosalind C. et Grace K. Baruch (1987). "Determinants of Fathers' Participation in Family Work ", Journal of Marriage and the Family, vol. 49, no 1, $29-40$.

BENOKRAITIS, Nijole (1985). "Fathers in the Dual-Earner Family", in Shirley Hanson et Frederick Bozett (sous la direction de). Dimensions of Fatherhood, Beverly Hills, Sage, 243-268.

BOZETT, F.W., S.M-H Hanson (eds) (1985), Perspectives on fatherhood, Beverly Hills, California, Sage.

BRONSTEIN, P., C.P. Cowan (eds) (1988), Fatherhood Today: Men's changing role in the family, New York, Wiley.

CASTELAIN-MEUNIER, Christine (2002). La place des hommes et les métamorphoses de la famille, Paris, PUF, $192 \mathrm{p}$.

COURNOYER, M. (1995). Grossesse, Maternité et Paternité à l'Adolescence. Recueil de recension des écrits, Montréal, Québec. Institut Québécois de Recherche sur la culture.

CROUTER, Ann, M. Perry-Jenkins, T.L. Huston et S.M. McHale (1987). "Processes Underlying Father Involment in Dual-Earner Families", Developmental Psychology, vol. 23, 431-440.

DELAISI de Parseval, Geneviève (1981). La part du père, Paris, Seuil, 319 p.

DELUMEAU, Jean et Daniel Roche (1990). Histoire des pères et de la paternité, Paris, Larousse, 477 p.

DE SINGLY, François (1993). Sociologie de la famille contemporaine, Paris: Nathan, 1993.

DIENHART, Anna (1998). Reshaping Fatherhood. The Social Construction of Shared Parenting , Thousand Oaks, Sage, 245 pages.

DYCKE, Nathalie et Jean-François Saucier (1999). Cultures et paternités, Montréal, Saint-Martin, 143 p.

ERICKSON, R., V. Gecas (1991), "Social Class and Fatherhood", in F. Bozett et S. Hanson, Fatherhood and Families in Cultural Contexts, New York, Springer, p.114-137

FERRAND, Michelle (1981), "La paternité dite par les hommes", Le groupe familial, N. 92: 60-64.

FOURNIER, François et Anne Quéniart (1994). Les formes contemporaines du rapport à la parentalité chez les pères québécois: essai de typologie sociologique, rapport de recherche, Laboratoire de recherche en écologie humaine et sociale, UQAM, $151 \mathrm{p}$.

FRENCH, R., J. Thomas. (1999). "Maturity and Education, Citizenship and Enlightment: An Introductin to Theodor Adorno and Hellmut Becker, Education for maturity and Responsibility". History of The Human 
Sciences, 12(3) : 1-19.

GAUDET, S. (2001). "La responsabilité dans les débuts de l'âge adulte", Lien social et Politique, 46, automne, 71-84.

GILLIGAN, C. (1993). In a Different Voice, Cambridge and London: Harvard University Press.

GLASER, B. G. (1978). Theoretical Sensitivity: Advances in the Methodology of Grounded theor. Mill Valley, CA : Sociology Press.

GLASER, B. G. et A. L. Strauss (1967). The Discovery of Grounded Theory. Strategies for Qualitative Research, Chicago : Aldine Press.

IISHII-KUNTZ, M. (1994), "Paternal Involvement and Perception Toward fathers' Role: A Comparison Between Japan and the United States", Journal of Family Issues, Vol.15, No.1, p. 30-48.

KISELICA, M.S. (1995) Multicultural counseling with teenage fathers. Thousand Oaks, California, Sage Book.

LAMB, M.E. et al. (1987), The Father's Role: Cross Cultural Perspectives, Hillsdale (New Jersey), L. Erlbaum.

LÉVESQUE, P-A., M. Perrault, C. Goulet (1997), "La paternité en milieu défavorisé : le point de vue d'intervenants sociaux". Père à part entière, sous la direction de J. Broué et G. Rondeau, Montréal, Éditions Saint-Martin, p. 91-112.

MCBRIDE, B.A. (1989), "Stress and father's parental competence: Implications for family life and parent educators, Family Relations, Vol. 38, 385-389.

MÉNARD, A-M (1999), La vision du rôle paternel et les pratiques auprès des pères de milieux défavorisés d'infirmières oeuvrant dans les services de périnatalité en CLSC. Mémoire de maîtrise en psychologie, Université du Québec à Montréal, 1999.

PERRY-JENKINS, Michaël et Ann Crouter (1990). "Men's provider Role Attitudes", Journal of family Issues , Vol. 11, 136-156.

QUÉNIART, Anne (2002b), "Place et sens de la paternité dans les projets de vie des jeunes pères", Comprendre la famille, Tome 6, sous la direction de Gilles Pronovost, 55-76.

QUÉNIART, Anne (2002a). "La paternité sous observation: des changements, des résistances mais aussi des incertitudes", dans Descarries, Francine et Christine Corbeil (sous la direction de). Espaces et temps de la maternité, Montréal, remue-ménage, 501-522.

QUÉNIART, A., Lachance E. (1995) Les études socio-historiques sur la paternité : transformations sociohistoriques, représentations et pratiques. LAREHS, Université du Québec à Montréal.

ROBINSON, B.E.(1988) Teenage fathers. Toronto, Lexington Books.

ROBINSON, Bryan E., BARRETT Robert L. (1986), The Developing Father: Emerging Roles in Contemporary Society, New York, Guilford.

ROTONDO, Anthony, E. (1985). "American Fatherhood", American Behavioral Scientist, 7-25.

RUSSELL, Graeme (1982). "Highly Participant Australian Fathers: Some Preliminary Findings", Merril Palmer Quartely, vol. 28, no 1, 137-156.

SCHÜTZ, A. (1987). Le chercheur et le quotidien: phénoménologie des sciences sociales, Paris, Méridiens Klinksieck.

SENNETT, Richard (1979) Les tyrannies de l'intimité, Paris, Seuil.

TURCOTTE, Geneviève (1994), L'implication paternelle: déterminants et modèles d'intervention, Les cahiers d'analyse du GRAVE, Laboratoire de recherche en écologie humaine et sociale, Montréal.

VOLLING, Brenda et Jay Belsky (1991). "Fathers' Involvement with Infants in Single- and Dual-Earners Families", Journal of Marriage and the family , Vol 53, no 2, 461-474. 